\title{
Sobre el Derecho a la Resistencia en Immanuel Kant
}

Adriana Vera Díaz

Colombia

doi: http://dx.doi.org/10.18273/revfil.v18n2-2019002 (c) (†) 


\title{
Sobre el Derecho a la Resistencia en Immanuel Kant*
}

Resumen: los escritos en los cuales Kant habla sobre la posibilidad de ejercer un derecho de resistencia, es notable su firme desacuerdo al mismo, al calificar la acción de resistencia como totalmente inadmisible y se considera por tanto el peor de los delitos; dicha postura lo lleva a conservar la preponderancia del orden actual del Estado. Sin embargo, es fácil presuponer que la resistencia, junto con las implicaciones y los recursos que esta considere necesarios, fuera considerada como la respuesta lógica ante las injusticias para quien se le ha adjudicado dentro de la tradición de los pensadores de la libertad. En el presente escrito enfocaremos la atención en el filósofo alemán, desarrollando una descripción de sus argumentos frente a su postura antes mencionada, y las contradicciones que se han presentado en sus ejes temáticos del ámbito político.

Palabras clave: resistencia, Estado, sociedad, justicia, filosofía política, Kant.

\section{On the Right to Resistance in Kant}

\begin{abstract}
Kant talks about the possibility of exercising a right of resistance, it is remarkable his firm disagreement to the same one, when qualifying the action of resistance as totally inadmissible and is therefore considered the worst of the crimes; this position leads him to conserve the preponderance of the present order of the State. However, it is easy to assume that resistance, together with the implications and resources it deems necessary, would be considered the logical response to the injustices for those who have been adjudicated within the tradition of freedom thinkers. In this paper we will focus on the German philosopher, developing a description of his arguments against his aforementioned position, and the contradictions that have been presented in his thematic axes of the political sphere.
\end{abstract}

Keywords: resistance, State, society, justice, political philosophy, Kant.

Fecha de recepción: 30 de junio de 2018

Fecha de aceptación: 16 de enero de 2019

Forma de citar (APA): Vera-Díaz, A. (2019). Sobre el Derecho a la Resistencia en Immanuel Kant. Revista Filosofía UIS, 18(2), doi: 10.18273/revfil.v18n2-2019002

Forma de citar (Harvard): Vera-Díaz, A. (2019). Sobre el Derecho a la Resistencia en Immanuel Kant. Revista Filosofía UIS, 18(2), 17-34.

Adriana Vera Díaz: colombiana. Magíster en Filosofía de la Universidad Industrial de Santander.

Correo electrónico: cony877@hotmail.com

ORCID: 0000-0003-3183-0501

"Artículo de reflexión derivado de investigación. 


\section{Sobre el Derecho a la Resistencia en Immanuel Kant}

El problema que ocupó a Kant en los últimos años pareciera ser la organización de un Estado que pueda armonizar con el dictado de la razón pura práctica; es decir, con el constructo de su filosofía política. Para el filósofo prusiano el hombre tiene una fuerte pretensión de socializar, pues así al experimentar el proceso de sus posiciones naturales siente más su condición de hombre pero al mismo tiempo posee una fuerte predisposición de separarse porque encuentra en sí mismo una cualidad insociable donde quiere doblegar todo a su deseo (cfr. Kant, 2003a, p. 107); esa "insociable sociabilidad" (107); como conocemos el antagonismo propuesto por Kant, es el medio que la Naturaleza ha propiciado para que los seres humanos lleguemos a un orden legal, de ahí que en virtud del nombrado antagonismo han sido necesarias las guerras y las disputas para que el hombre entienda que sus acciones se deben cimentar en la razón, pues esta ordena a priori los imperativos categóricos del deber ser. Por ello, para comprender mejor cómo se desarrolla dicho antagonismo, repasemos las palabras de Kant: "El hombre quiere concordia, pero la Naturaleza sabe mejor lo que es bueno para su especie y quiere discordia. El hombre pretende vivir cómoda y placenteramente, mas la Naturaleza decide que debe abandonar la laxitud y el ocioso conformismo" (2003a, p. 109).

Siendo así, la Naturaleza en la teoría kantiana desempeña funciones como: llevar en sí el propósito teleológico de realización plena, como una "valoración ética en el sentido de no ir en contra de la Naturaleza, [...] y amparo del progreso humano hacia lo mejor y la paz perpetua" (Barrientos, 2001, p. 859); entonces, desde la insociable sociabilidad nace la pretensión de constituir un conjunto de normas jurídicas que se estructuren en una constitución civil, que envuelva las actitudes e ideologías de los individuos y se posibilite su desarrollo entre el entorno social, estableciendo, a su vez, el derecho, la agremiación Estatal y la proyección hacia una paz perpetua ${ }^{1}$ :

Una sociedad en la que la libertad bajo leyes externas se encuentre vinculada en el mayor grado posible con un poder irresistible, esto es, una constitución civil perfectamente justa, tienen que ser la tarea más alta de la naturaleza para con la especie humana (Kant, 2003a, p. 110).

\footnotetext{
${ }^{1}$ En alusión al texto kantiano Sobre la paz perpetua (2012), y al lema irónico correspondiente a la paz perpetua colocado cerca de un cementerio en el cartel de un restaurante holandés, que Kant menciona al inicio de su obra.
} 
A partir de este enfoque encontramos entre los estudios de Hannah Arendt, sin temor a tergiversaciones, la aseveración: "El núcleo de sus preocupaciones pasó a ser sobre todo aquello que hoy en día denominamos derecho constitucional" (2012, p. 37); en consecuencia, uno de los temas de los que hace mención en los textos pertenecientes a sus últimos años es sobre el Derecho a la Resistencia; la postura de Kant frente al mismo se puede considerar como polémica en cuanto a la aparente contradicción de su pensamiento.

En un primer momento, el filósofo prusiano considera la revolución histórica como un acto decisivo para fundamentar la comprensión del género humano y la posibilidad esperanzadora del cumplimiento de las metas morales que provienen de su condición de criatura racional. Aunque Kant no es muy partidario de la violencia y las implicaciones que conllevan las revoluciones, pues la sedición y los medios violentos que la identifican no pueden tener justificación racional alguna (cfr. Bilbeny, 1989, p. 30), el filósofo hizo parte como espectador de la Revolución Francesa desde su lugar de origen, de la cual realizará un análisis moralista tomándola como el acto más significativo de la época, y que se puede considerar como un "signo histórico" que permite ver cómo el ser humano está en búsqueda constante del progreso moral. Así, en El Conflicto de las Facultades afirma que tal suceso:

Encuentra en el ánimo de todos los espectadores [...] una simpatía conforme
al deseo que colinda con el entusiasmo y cuya propia exteriorización llevaba
aparejado un riesgo, la cual no puede tener otra causa que una disposición
moral en el género humano. En esta causa moral confluyen dos cosas: en
primer lugar, el derecho a que un pueblo no haya de verse obstaculizado
por poder alguno para darse una constitución civil tal como le parezca bien
a él mismo; en segundo lugar, la meta (que al mismo tiempo es un deber)
de que aquella constitución de un pueblo sólo sea jurídica y moralmente
buena en sí, cuando su naturaleza sea de tal índole que pueda evitar con
arreglo a principios la guerra ofensiva, constitución que no puede ser sino la
constitución republicana (Kant, 2003b, p. 160).

Sin embargo, de lo anterior no debe concluirse que el filósofo simpatizará con los futuros revolucionarios porque si bien hay "derechos" — como aquel que ayuda al pueblo a asegurar la autodeterminación racional del hombre (la libertad)—; Kant en una nota al pie de página esclarece que, aunque le pertenezca al pueblo el derecho de ser colegislador, este lo defenderá solo por amor a la libertad, por consiguiente:

ese derecho siempre es tan solo una idea cuya realización queda limitada por la condición de que sus medios concuerdan con la moralidad, algo que al pueblo no le cabe transgredir jamás; no resulta lícito que esto tenga lugar mediante la revolución, que en todo momento es injusta (2003b, p. 160). 
Por tanto, ningún soberano intentará obstruir al pueblo por miedo a una posible sublevación, puesto que, hace parte de la justicia el ser partícipes de una sociedad política y del deber ser: "la justicia es la condición en que nos hemos garantizado recíprocamente nuestros derechos; existe sólo donde hay gobierno" (Korsgaard, 1996, p. 282); de ahí que el gobierno se funde en nuestra voluntad de justicia. Así mismo, el filósofo de Königsberg manifiesta que la razón prácticomoral dictamina en el sujeto un rechazo inapelable; a saber, "no debe haber guerra" entre sujetos dentro del estado de naturaleza, ni menos entre los sujetos como Estados legales, debido a que este no es el modo como se debe gestionar el derecho.

Así, sus argumentos en contra del supuesto derecho a la revolución los expone Kant en obras como Teoría y práctica (1986), La metafísica de las costumbres (1993) y Sobre la Paz Perpetua (2012); en donde sostiene que bajo ninguna circunstancia se puede recurrir a un presunto derecho de resistencia, inclusive si esta fuese el único medio para batallar una situación injusta. La revolución no es legítima porque:

Toda oposición contra el supremo poder legislativo, toda incitación que haga pasar a la acción el descontento de los súbditos, todo levantamiento que estalle en rebelión, es el delito supremo y más punible en una comunidad, porque destruye sus fundamentos (Kant, 1986, p. 40).

Aquí Kant llega a manifestar que el pueblo debe soportar un abuso del poder supremo, inclusive un abuso intolerable, debido a que su resistencia a la legislación suprema ha de comprenderse contraria a la ley y hasta destructora de la constitución legal, dado que tendría que existir una ley pública que autorice al pueblo resistirse (cfr. Kant, 1993, p. 152); así, en palabras de Ceballos "En una Constitución ya establecida el pueblo no tiene más el derecho a determinar la forma en que dicha Constitución debe ser gobernada. Si conservara dicho derecho entonces habría un conflicto consistente en saber" (2015, p. 108); de esta forma, se generaría una nueva problemática al escoger un juez que determine en qué lado se encuentra el derecho, presentándose a su vez la imposibilidad de un "derecho de necesidad" ${ }^{2}$ ", porque este no levanta la barrera que limita el poder propio del pueblo. Beade señala al respecto:

La razón de ello es que, una vez que el pueblo ha delegado el poder de promulgar las leyes, no retiene el derecho de emitir juicio acerca del modo en que sus representantes hagan uso del poder que se les ha transferido [...]. No sólo es contradictorio otorgar al pueblo el derecho a emitir juicio respecto de la legitimidad de las leyes [...], sino que además la resistencia a la autoridad constituida implicará la disolución misma del Estado de derecho (2009, pp. 31-33).

\footnotetext{
${ }^{2} \mathrm{El}$ derecho de necesidad (ius in casu necessitatis), lo presenta Kant como un pretendido derecho a cometer injusticia en caso de necesidad extrema (física) (cfr. Kant, 1986, p. 41).
} 
Parece pertinente dejar claro que la forma de institución de un Estado civil recibe el nombre de contrato originario, el cual Kant (1986) describe como la "coalición de cada voluntad particular y privada, dentro de un pueblo, para constituir una voluntad comunitaria y pública" (p. 36); es decir, en la idea del contrato originario kantiano este no consiste en la ejecución de un tipo de consenso social, sino un principio de legitimidad que logre dar cuenta de cómo debe ser pensada la unión de la comunidad que está en la base del principio universal del derecho, pues en tal contrato los hombres manifiestan la voluntad de abandonar la condición no política (estado de naturaleza) y pasar a una situación política (Estado civil). Dicho de otra forma, que el contrato original en Kant sea un concepto de la razón con realidad práctica indica que la coalición de toda comunidad no reside en un acuerdo mutuo celebrado empíricamente. Una idea es capaz de establecer un nuevo pacto, indicando una posible unión sistemática de todos los integrantes de una comunidad, que de ninguna forma podría obtenerse por medio de un consenso. Beade lo sintetiza de la siguiente manera: "el contrato no es para Kant un acontecimiento histórico. Kant lo entiende [...] en tanto principio a priori de la razón práctica sobre el cual descansa la legitimidad de una constitución política" (2007, pp. 59-73).

De acuerdo a lo antes dicho surge una pregunta relevante, a saber: ¿entonces qué debe hacer un pueblo que considera posible perder su felicidad bajo cierta legislación? Para Kant es claro que: "La respuesta sólo puede ser la siguiente: no le queda más remedio que obedecer" (1986, p. 38). Como afirma en su texto Crítica de la Razón Práctica la felicidad es el anhelo de todo ser racional que se funda materialmente en su facultad de desear, empero como ese material determinante es conocido empíricamente por el sujeto resulta imposible considerar esto como una ley, ergo en el deseo de felicidad no resulta importante la configuración de la conformidad de las leyes sino de la materia. En este sentido, el principio de legalidad prevalece sobre los principios de justicia, aun cuando la injusticia de la rebelión se basa en la idea a priori del contrato originario (cfr. Bau, 2004, p. 191). Así que:

El soberano quiere hacer feliz al pueblo según su concepto, y se convierte en déspota. El pueblo no quiere renunciar a la general pretensión humana de ser feliz y se vuelve rebelde. [...] Asimismo, resultará comprensible que, antes de existir la voluntad general, el pueblo no posee ningún derecho de coacción contra quien le manda, porque sólo a través de éste puede aquél coaccionar jurídicamente (Kant, 1986, p. 44).

Acá no se trata de la felicidad que el pueblo pueda aguardar de una organización o de un gobierno, sino del derecho que por ese medio debe ser garantizado a cada uno; es claro que en una sociedad existe entre los individuos - en cuanto súbditos - un poder legítimo que permite imponerse o prevalecer ante los demás dentro de los actos jurídicos. Kant lo deja claro cuando señala que 
"según el derecho todos, en cuanto súbditos, son iguales entre sí, porque ninguno puede coaccionar a otro sino por medio de la ley pública" (1986, p. 29), pero de esa condición de súbdito se excluye al jefe de la comunidad, por ser quien originó la ley pública o quien la conserva, pues no se considera como miembro de la misma.

Por lo tanto, en la aceptabilidad de las leyes el dominio es del legislador; porque este valiéndose del derecho del soberano, es quien habilita el principio del contrato originario como precepto para estimar si una ley coincide o no con el principio del derecho. No olvidemos que, para el filósofo en cuestión, es al jefe supremo a quien concierne de manera indirecta la conservación del pueblo imponiendo de alguna manera la obligación de "tomar como máxima el obrar conforme al derecho (la cual) es una exigencia que me hace la ética" (Kant, 1993, p. 40). Lo anterior lleva a Beade a afirmar que el principio en el cual Kant se basa para negar todo derecho de resistencia es el de la preservación del propio Estado de derecho — conseguida esta preservación a como dé lugar — originando de esta manera la necesidad de una obediencia absoluta.

Precisamente como resultado se genera uno de los argumentos de Kant en oposición al derecho de resistencia, este es la ruptura oficial de la constitución como secuela de la aceptación de un derecho que fuese autodestructivo por generar una contradicción en el Estado de derecho. En palabras del autor:

Resulta claro que el pueblo, con este modo de buscar sus derechos, ha cometido injusticia en altísimo grado, porque tal modo de proceder (una vez aceptado como máxima) torna insegura toda constitución jurídica e introduce un estado de absoluta ausencia de ley (status naturalis) en el que todo derecho cesa, cuando menos, de surtir efectos (Kant, 1986, p. 43).

Es decir, en el caso donde el poder del Estado da efectividad a la ley no consentiría la resistencia, puesto que, si una ley que es irreprochable desde la legalidad, y que se encuentra unida no sólo a la facultad de coaccionar sino a la prohibición de establecer oposición alguna al legislador, no permitiría la existencia de una comunidad jurídicamente establecida (cfr. Ceballos, 2015, p. 107), por ende, si se reconoce este tipo de leyes injustas se estaría negando la legitimidad de la constitución y negando así mismo el principio de derecho; por consiguiente: "ahí se halla la piedra de toque de la legitimidad de toda ley pública. Si esa ley es de tal índole que resultara imposible a todo un pueblo otorgarle su conformidad [...] entonces no es legítima" (Kant, 1986, p. 37). Esto quiere decir que el impedimento de resistir a la autoridad imperante es incondicionado en absoluto, así que el súbdito no puede resistirse por medio de la contraviolencia aun en el caso donde la autoridad llegara a transgredir el pacto originario, transformando de esta manera al gobierno en tirano o despótico. 
La idea para el filósofo es que la confrontación súbdito-soberano ha de entenderse como un momento en el cual, "en la lógica del argumento trascendental, convendrá disiparse por el método de anteponer el gobierno estatuido" (Ceballos, 2015, p. 108); ergo "No existe derecho alguno de coacción por parte del súbdito contra el soberano, ya que sólo este ostenta todo derecho coercitivo y sólo a través de él lo detenta cada uno frente a sus conciudadanos" (Kant, 2003a, p. 265). En otras palabras, el pueblo no tiene derecho a la resistencia porque es la ley la que confiere dicho derecho, por ende, permitimos una serie de principios regulativos en el instante en que se instaura una Constitución civil, la cual, nos señala que es solo derecho del súbdito generar coacción ante el pueblo en pro del perfeccionamiento moral ${ }^{3}$ de los sujetos, sin pasar por encima de las normas jurídicas establecidas. En atención a lo cual:

Si mediante la violencia de una revolución, generada por una mala Constitución, se hubiera logrado por vías antijurídicas otra Constitución más conforme a la ley, no debería permitirse ya retrotraer al pueblo de nuevo a la antigua, aunque, durante la vigencia de ésta, todo aquel que perturbara el orden con violencia o astucia debía ser sometido justamente a las sanciones del revolucionario (Kant, 2012, p. 87).

Por lo tanto, donde se encuentre instaurada una constitución, considerada más acorde al derecho por medio de la revolución, no es legal encaminar al pueblo a la normativa anterior, aunque no se trata de dar una entrada a la probabilidad de justificar abiertamente las revoluciones. De hecho, Kant en una nota al pie trata del discernimiento de jerarquía entre dos extremos de la política, es decir entre la injusticia y la anarquía, en vista de que "cualquier constitución jurídica, conforme al derecho, aunque sea en pequeño grado, es mejor que ninguna; una reforma precipitada encontraría su último destino (la anarquía)" (2012, p. 87). Sin embargo, para el prusiano la anarquía no es una alternativa en caso de que no exista usucapión, aun cuando el despotismo se llegue a expresar en su forma más extrema, como es el caso de la tiranía; a pesar de ello "como una muestra de hasta qué punto Kant sabe que su posición es también moralmente contraintuitiva" (Ceballos, 2015, pp. 110), el filósofo prusiano atenúa dicha negativa en la misma aclaración de pie de nota cuando expresa que:

Utilizará, en cambio, las revoluciones, donde las produzca la naturaleza por sí misma, no para disimular una opresión aún mayor sino como una llamada de la naturaleza a instaurar mediante reformas una Constitución legal, fundada en los principios de la libertad (Kant, 2012, p. 87).

Es aquí, donde podemos encontrar la posible contradicción de su pensamiento debido a que Kant se presenta como un defensor de la soberanía popular con un espíritu libertario, en vista de que reprende a los gobernantes y los induce a estar

${ }^{3}$ Cabe señalar que para Kant "No puede existir, por tanto, ninguna disputa entre la política, como teoría del derecho aplicada, y la moral, como teoría del derecho, pero teorética" (1986, p. 83). Porque romper los vínculos del Estado sin anticiparse a una nueva constitución es ir en contra de la prudencia. 
atentos a ese llamado natural. Al respecto Onfray dice que, si bien es cierto que Kant extendió la invitación a reflexionar, también limitó al prohibir dudar sobre los fundamentos del orden social; de esta manera se comprende que la reflexión requiere el entendimiento, pero para los fines y la acción pública solo nos basta la obediencia (cfr. Onfray, 2011, p. 257). Así mismo, Kant plantea que junto al temor de toda anarquía está vigente la reclamación de libertad y dicha libertad solo se puede conseguir por algún tipo de revolución, pero al mismo tiempo continúa con severidad su postura conservadora, pues "El reformismo o la revolución están prohibidos de hecho y, para desactivar toda veleidad reivindicativa, se institucionaliza la caridad en los espíritus y las instituciones que sirven de albergue a estas ideas conservadoras" (Onfray, 2011, p. 173).

Al reanudar su raciocinio sobre la ilegalidad de la rebelión en el apéndice segundo de su texto Sobre la Paz Perpetua, Kant se refiere a la maldad de la naturaleza humana que hace necesaria la coacción, mencionándola como un todo empírico que implica el concepto del derecho público denominada "fórmula trascendental" con la siguiente sentencia: "Son injustas todas las acciones que se refieren al derecho de otros hombres cuyos principios no soportan ser publicados" (2012, p. 100); por ello en esta oportunidad puede solventar todo tipo de contienda en cuanto a la mencionada ilegalidad a través de lo que él designa como "principio trascendental de la publicidad", dado que "no basta con contemplar este principio como ético, resulta primordial considerarlo como jurídico" (Flores y Espejel, 2008, p. 58).

Entonces, si al instaurar una Constitución política se le establece al pueblo un poder legítimo y en determinadas circunstancias del uso de la fuerza contra la autoridad suprema, en tal caso dicha autoridad no sería tal; y si se pusieran ambos a sí mismos como condición de la instauración del Estado, esta no fuese posible ya que se contradice la voluntad del pueblo (cfr. Kant, 2012, p. 101). Pues, de acuerdo con el argumento del pensador, la perversión puede ser enfrentada mediante la publicidad o la claridad de las acciones públicas, con el fin de actuar siempre con justicia y en el marco de la moral (cfr. Flores y Espejel, 2008, p. 46).

En tal caso, la ilegalidad de la rebelión se hace perceptible porque la máxima en la que se funda no se puede poner de manifiesto al público sin destruir el propósito del Estado, lo que hace indispensable mantenerla oculta. En palabras de Kant: "La injusticia de la rebelión se pone de manifiesto, por tanto, en que, si se confesara públicamente sus principios, no se podrían realizar sus propios propósitos. Habría que mantenerlos en secreto necesariamente" (2012, p. 101). Mientras que el soberano no precisa ocultar nada y puede decir libremente que castigará toda revolución, "aunque éstos [los cabecillas revolucionarios] sigan creyendo que aquel había transgredido primero la ley fundamental" (Kant, 2012, p. 102). Kant sigue afirmando que el jefe de Estado no debe preocuparse de que la publicación de sus principios frustre sus propósitos si él es consciente de 
poseer el supremo poder irresistible, concluyendo a su vez que, si una rebelión triunfa, el soberano vuelve a la condición de súbdito sin que se le permita iniciar una nueva revuelta para regresar a su antiguo puesto. En este punto es evidente que la revuelta victoriosa es aceptada como acontecimiento político que obtiene legalidad y que también representa un progreso hacia un Estado de derecho; sin embargo, inmediatamente corrobora su ilegitimidad y se libra de responsabilidad al soberano depuesto.

De esta forma, el argumento de la publicidad es un modo del argumento trascendental que abarca las particularidades ya mencionadas a su alrededor; a saber, la discrepancia a todo mandato jurídico y el retroceso interminable en el enfrentamiento por la potestad entre dos autoridades. Lo que despierta aquí el interés es que el gobernante no precisa presentar su amenaza de punición por ser el poseedor del poder supremo irresistible ${ }^{4}$. Aquí se enuncia la indeterminación de la estructura contractual del filósofo prusiano. Empero, en los textos que se mencionarán a continuación, mantendrá una postura opuesta en cuanto al soberano y el orden establecido.

Observemos cómo Kant se ocupa también de los asuntos políticos en La Metafísica de las Costumbres, comprendiéndolos en el sistema de la filosofía práctica, particularmente en lo que concierne al derecho público. Por esta razón el derecho público incluye el derecho político, el derecho de gentes y el derecho cosmopolita. De allí que, en Kant, considerar la teoría en la práctica política es llevar las máximas de las acciones al principio universal de derecho cuya indagación está en la creación y la operatividad de un Estado civil (cfr. Ceballos, 2015 , p. 114) conforme a los principios que posee y que responden a los tres estados jurídicos en los que se encuentra cada sujeto por naturaleza, esto es, libertad, igualdad e independencia.

De este modo, en la segunda parte del libro, titulada Doctrina del Derecho, se dan las condiciones de la autonomía del Estado; en otros términos, se esclarece la forma en la que el Estado se configura y se mantiene a sí mismo en conformidad con las leyes de la libertad (cfr. Kant, 1993, p. 149). De esta manera, queda claro que la función del gobernante es desarrollar las leyes mas no divulgarlas; pues este está sujeto a la norma y, por consiguiente, al soberano. A su vez el soberano puede quitarle el poder al gobernante, destituirlo o cambiar su mandato, pero no castigarlo; porque el castigo corresponde a un acto de poder ejecutivo al cual corresponde — según la ley_ la potestad de coacción, por lo que él no puede ser coaccionado debido a que sería una contradicción (Kant, 1993, p. 148). Lo antes mencionado debe entenderse como un efecto del argumento de soberanía por el fuero del jefe de Estado ante un probable castigo si es apartado de su cargo y aun ante la coerción como resultado de una rebelión.

${ }^{4}$ Kant menciona que el poder es irresistible en toda constitución civil "porque la que no tiene poder bastante para proteger a unos frente a otros tampoco tiene el derecho de mandarlos" (Kant, 2012, p. 102). 
Prosiguiendo con el tema que acá nos ocupa, sobre la rebelión o el derecho de resistencia, en este mismo apartado Kant determina que al súbdito no le es posible escudriñar en los fundamentos del orden civil un pretendido derecho para cancelar su obediencia. Así mismo, lanza la sentencia de que toda autoridad proviene de Dios y que, aunque no hay con tal expresión un fundamento histórico de la constitución civil, es una idea pura del principio práctico de la razón. El filósofo de Königsberg continúa su disertación fundamentando que la probabilidad de que un poder en el Estado pueda resistir a la máxima autoridad cuando aquel transgrede las leyes es algo discordante, por ende:

[...] el soberano en el Estado tiene ante el súbdito sólo derechos y ningún deber (constrictivo). Además, si el órgano del soberano, el gobernante, infringiera también las leyes, por ejemplo, procediera contra la ley de la igualdad en la distribución de las cargas públicas, en lo que afecta a los impuestos, reclutamientos, etc., es lícito al súbdito quejarse de esta injusticia (gravamina) pero no oponer resistencia ${ }^{5}$ (Kant, 1993, p. 150).

Aunque el soberano hiciere lo que hiciere no se le puede someter a juicio pues no se encuentra en la obligación jurídica de respetar las leyes civiles; aunque sí tiene unos límites de hecho o derivaciones del derecho imperfecto; por ello, se fundamenta el carácter absoluto del poder del Estado y la impunidad para el accionar del soberano, pues solo la libertad de poder de este puede hacer que los pactos establecidos sean obligatorios (Mirete, 1986, p. 139). Por esta razón al pueblo solo le pertenece el poder legislativo y sus representantes, como diputados que son, no pueden tornarse en un poder restrictivo; un organismo de derecho así compuesto es inadmisible. Sin duda la conclusión que nos presenta Kant (1993) es:

No hay, por tanto, resistencia legítima del pueblo; porque sólo la sumisión a su voluntad universalmente legisladora posibilita un estado jurídico; por tanto, no hay ningún derecho de sedición (seditio), aún menos existe el derecho de atentar contra su persona ${ }^{6},[\ldots]$ so pretexto de abuso de poder. El menor intento en este sentido es un crimen de alta traición (pp. 151-152).

Cabe preguntarse ipor qué debe el pueblo soportar el abuso de poder? La respuesta del filósofo es clara: porque su rebeldía a la constitución discrepa con la ley. Para que el pueblo esté habilitado para la resistencia es necesario que haya una ley pública donde se autorice dicha acción. Kant finaliza este apartado opinando que todo cambio en la constitución, que bien puede ser necesario, debe hacerse por medio de reformas introducidas por la autoridad, mas no de revoluciones hechas por el pueblo. Asimismo, aclara que sí se da una revolución solo afectaría al poder ejecutivo y no al legislativo, dado que para Kant estos dos poderes deben estar separados, pero el primero debe estar subordinado al

${ }^{5}$ Cursiva propia.

${ }^{6}$ Entiéndase aquí de quien detenta el poder. 
segundo. Por esta razón el poder ejecutivo es un poder subalterno, la persona que lo detenta es responsable frente al legislativo que en cualquier momento puede destituirlo. Igualmente, explica que en caso tal de que la rebelión triunfe, el pueblo debe obedecer al nuevo régimen sin importar la injusticia con la cual inicia. Además, el jefe supremo derrocado no puede ser demandado por sus acciones cuando detentaba el poder ${ }^{7}$.

Kant al hacer énfasis sobre el problema en cuestión afirma que es inútil procurar indagar el origen histórico del mecanismo del Estado ya que puede ser objeto de conjetura, aunque cambiar por la fuerza la constitución existente es punible. Lo anterior, debido a que el pueblo se amotinaría para tal fin: "la insurrección bajo una constitución ya existente es una subversión de todas las relaciones jurídico-civiles y, por tanto, de todo derecho" (Kant, 1993, p. 178). Así, continúa sosteniendo que las formas del Estado solo representan la legislación originaria del Estado civil; sin embargo, el espíritu del pacto originario implica adecuar la forma de gobierno a una "república pura", dado que esas formas empíricas (estatutarias) solo sirven para el sometimiento del pueblo, mientras que la forma originaria (racional) o republicana tiene como principio la libertad, inclusive actúa como condición de toda coacción necesaria para una constitución jurídica (cfr. Kant, 1993, p. 179).

Kant finaliza estableciendo que "mientras aquellas formas de Estado, según la letra, tengan que ser representadas por otras tantas personas morales investidas de poder supremo, solo puede admitirse un derecho interno provisional y no un estado de la sociedad civil absolutamente jurídico" (1993, p. 179). En consecuencia, al no prevalecer el derecho no se produce contradicción en el momento que se le contrapone la resistencia, pues siempre sustentó que es inconciliable una aspiración de derecho contra el derecho consolidado, lo que en esta oportunidad no sucede. De igual forma, como conclusión final de este apartado sobre los principios metafísicos del derecho, Kant insiste en la imposibilidad racional del cambio revolucionario como método de lograr el bien supremo, como lo es la paz perpetua, porque mientras tanto se ocasionará un momento de decadencia de todo Estado jurídico.

Hasta aquí se observa cómo en Kant es inteligible que el rechazo al derecho de resistencia y oposición se acople al sistema racional del filósofo en un modelo argumentativo en donde aparecen explicaciones empíricas y prudenciales. Esta postura convive sosegadamente en el contexto de las ideas políticas y morales del pensador prusiano. De allí la propuesta de Hannah Arendt en sus Conferencias sobre la filosofía política de Kant de otorgar un breve esclarecimiento

\footnotetext{
${ }^{7}$ Kant añade un privilegio al soberano y es el derecho a emprender una contrarrevolución con ayuda extranjera, gracias a la injusticia vivida; generando incongruencia con lo estipulado previamente: "[...] si la rebelión del pueblo triunfa, aquél vuelve a la situación de súbdito, sin poder comenzar ninguna rebelión para recuperar su situación anterior" (cfr. Kant, 2012, p. 102). Lo que lleva a debilitar toda inclinación hacia el favorecimiento de la autoridad.
} 
a la supuesta contradicción que se manifiesta en Kant sobre la resistencia y sus concurrentes elogios iniciales a la Revolución Francesa. La filósofa se expresa ante tal incongruencia y afirma lo siguiente:

El choque entre el principio a partir del cual se actúa y el principio que rige el juicio. Kant, de hecho, condena la acción misma, aunque luego defiende sus consecuencias con una satisfacción rayana en el entusiasmo. Este choque no es una simple cuestión teórica (2012, p. 92).

De acuerdo con lo anterior, el pensamiento kantiano se deriva del citado principio político, a saber: el principio trascendental de la publicidad, cuyo planteamiento negativo tendría la acepción de un postulado preventivo el cual obtendría como oposición una máxima positiva convenientemente moral; ya que en su filosofía moral la publicidad es el criterio de rectitud. De suerte que se interprete esto como la solución que da Kant al conflicto entre moral y política donde puede admitirse la rebelión en el momento en que se dé por abolida la libertad de opinión; así, la filósofa alemana deduce "que la condena kantiana de la acción revolucionaria se basa en un malentendido" (Arendt, 2012, p. 114), pues Kant la comprende como un golpe de Estado. Hasta aquí Arendt ha desarrollado una íntegra dilucidación sobre los enfoques de Kant frente a la acción de resistir como insurrección.

Ahora bien, si volvemos al principio trascendental de la publicidad, se hace necesario manifestar que dicha disertación de los dos enunciados enfrentados de dicho principio no se podría mantener. Por esto, es más acertado comprenderlos como fórmulas íntegras del propio principio. En efecto, el segundo encauza la imperfección del primero al suministrar una advertencia que erradica los levantamientos injustos derivados de aquel que las puede hacer públicas bajo el principio de soberanía, aunque aquello no logra absolver la censura a toda resistencia.

Aquí hemos de referirnos también a la filósofa anglosajona Christine Korsgaard, quien reflexiona en el artículo Tomar la ley en nuestras propias manos: Kant sobre el Derecho a la Revolución (1996) en torno a la absoluta ambigüedad de la revolución, la

[...] autoridad legítima a la cual los ciudadanos tienen el deber de obedecer; y finalmente, nuestro entusiasmo por la Revolución Francesa [...], es un signo patente de la presencia de una disposición moral [...]. La justicia existe para preservar los derechos y la libertad de todos: esta es la idea y el ideal esencial de justicia. Pero todos sabemos que los procedimientos judiciales pueden ser usados contra esos mismos fines (1996, pp. 276-305).

Debido a que Kant reconoce la existencia de revolucionarios que se han unido por causas honorables como por razones corruptas, pensando así que los primeros deberían ser amonestados con menor severidad que los segundos. La revolución sería entonces un suceso en donde, frente a la arbitrariedad excesiva, 
el virtuoso — quien tiene la virtud de rectitud y no infringe la ley- experimenta la sensación de hacer justicia con sus propias manos para salvaguardar los derechos bajo su propia protección o velar por la competencia de la legislación ya que esta puede valerse de perversiones. Es así que:

Los órganos de justicia son usados para reforzar la injusticia; y lo que debería ser el recurso de los oprimidos, es la herramienta misma del opresor. En tales casos, la justicia, pervertida, se vuelve contra sí misma; los derechos humanos tienen necesidad de ser protegidos de la ley misma (Korsgaard, 1996, p. 306).

De acuerdo a la cita anterior, los sujetos al ser parte de un Estado pervertido donde la legitimidad del soberano acepta las injusticias, pueden tomar la decisión de proteger por sí mismos cada uno de los derechos y la eficiencia de la justicia, justificando esto como un acto virtuoso, puesto que: "tener derecho es justamente tener la autoridad ejecutiva para hacer valer un cierto derecho. Esto, a su vez, es el fundamento de la autoridad ejecutiva o coercitiva que tiene el Estado político" (Korsgaard, 1996, p. 278).

Es claro que Korsgaard reconoce que las conclusiones son más factibles, no por los escritos kantianos publicados, sino por el conocimiento que se tiene de su actitud en torno a las revoluciones de su época (cfr. 1996, p. 311). Ergo la claridad de la postura de Kant afirma la postura de la obediencia, pues esta se sostiene en el deber asimétrico. Al quebrarse dicha simetría nos encontramos frente a un hecho que, de acuerdo al argumento kantiano, es un deber; esto es obedecer y no resistir. De hecho, la dificultad reside en la supuesta separación entre el derecho y la moralidad, expuesto anteriormente, y el remedio que involucra la sumisión absoluta de la moralidad individual que propone el filósofo para las discordias entre dos frentes.

Recordemos las aseveraciones que Kant establece en el apéndice primero del texto Sobre la Paz Perpetua. Allí sentencia como algo ilegal retroceder al pueblo a la vieja constitución si una revolución triunfante y acorde al derecho natural, hubiera impuesto una nueva; llegado a este punto recordemos que lo anterior se ejecuta en el contexto de la declaratoria de la ilegalidad de la revolución. Así mismo en el ámbito de la aquiescencia de puniciones para los sublevados y la autorización a perpetuar el derecho público, aunque esté corrompido por la injusticia. Porque:

[...] si el derecho natural a la libertad como autonomía moral no es expresable en derecho positivo, de la misma manera no puede adoptar una forma jurídica positiva un derecho de rebelión perteneciente a aquel derecho natural a la libertad, entendida ésta como autonomía moral. Esa libertad sobre la que quisiera apoyarse un derecho legal a la resistencia sólo va a poder ser fijada mediante un movimiento moral, no a través de una acción legal (Bilbeny, 1989, p. 27). 
En cuanto a las críticas que algunos pensadores instauran, acerca de la idea de Kant de condenar toda revolución, no contiene ningún juicio valorativo, pues esta se puede refutar por los mismos enunciados que nos entrega el filósofo donde se puede observar el reconocimiento a los diferentes acontecimientos de resistencia y de manera simultánea los desaprueba por diferentes motivos, como se precisaron al inicio de este apartado, estos argumentos no se reducen a la pura oposición lógica del derecho imperante, pero sí podemos ser conscientes de que hay una insuficiencia en las demostraciones que den razón sobre qué o cómo admitir una perspectiva contraria en lo que puede ser legítimo.

Finalmente, nuestro enfoque del asunto parte de la seguridad de que el enfrentamiento de la perspectiva kantiana es esencial y no trata de soslayar el aspecto que deja ver ese Kant conservador; a pesar de ello todo indica que tampoco se reservan ni se subestiman las aserciones en las que se evidencia un Kant libertario y pensador de la independencia política. El rechazo del filósofo al derecho de resistencia y la postura en pro del hermetismo del poder soberano actual no se pueden exonerar con argumentos como los que se han expuesto a lo largo de este apartado, ni considerando un principio expositivo fundado en el temor de Kant a la censura.

Lo que se puede notar en los textos indagados es una constante fluctuación entre una posición muy cercana a la seguridad jurídico-política y una más cercana a un razonamiento donde la contienda aboga por la universalización de los bienes generados por la convivencia. Gracias a las varias argumentaciones que propenden solucionar este problema político, podemos contemplar las aseveraciones que favorecen a los jefes supremos, por decirlo de alguna manera, y de igual modo vemos un pensamiento significativo y reiterativo en contra del despotismo exteriorizado en la negación del derecho.

Por este motivo, Kant condena la dominación de la voluntad del otro, lo que considera como deficiente al sometimiento ante la necesidad dado que nunca renunció a la idea de perseverar el espíritu de libertad que se puede encontrar entre la subordinación y la insubordinación. Igualmente, deduce el mismo valor de la dignidad y la autonomía a la exigencia de las relaciones de todos los Estados sobre la cual estima la guerra como un mal menor dentro de la "fosa de la monarquía universal" aunque esta resulte como aquello moralmente inconcebible.

La noción de que sobre cada una de las voluntades es elemental un fundamento que articule cada una de estas, y así ajustarse a una voluntad general, es precisamente la idea que faculta la vehemencia para dar inicio a la ejecución de aquel modelo jurídico y la paz del Estado. En palabras del autor: 
[...] no basta para este fin la voluntad de todos los individuos de vivir en una constitución legal según los principios de la libertad [...] sino que es preciso, además, que todos conjuntamente quieran esta situación (unidad colectiva de la voluntad unificada) para que se instituya el todo de la sociedad civil; y como sobre esta diversidad de las voluntades particulares de todos hay que llegar a una causa unificadora para obtener una voluntad común, [...] en la realización de aquella idea (en la práctica), no se puede contar con otro origen del estado jurídico que la violencia (Gewalt), sobre cuya coacción se funda después el derecho público (Kant, 2012, pp. 84-85).

A pesar del irónico escepticismo en la bondad del soberano y de la certidumbre que pueda tener por parte del pueblo, Kant va en contra de este precepto teniendo en cuenta que dichas actitudes tan discrepantes se deben concebir en la forma de conferir al supremo la preferencia de fomentar lícitamente los cambios del Estado dando una mejora al Estado democrático sin desistir del principio popular de soberanía.

Por ende, debemos entender su hostilidad a la resistencia dentro del contexto de sus principios morales, pues los instrumentos de la insurrección involucran en gran medida a la violencia, por lo que rechaza la tradición donde se permitía el tiranicidio para salvar la república; aunque siguiendo su razonamiento del argumento trascendental también rechazó toda oposición coactiva. Kant con el objetivo de mantener el equilibrio en su hilo conductor argumentó que el dirigente debe permanecer sujeto a la ley, pero que al mismo tiempo se podría derrocar por el poder legislativo, es decir, por vías institucionales. Además, para el filósofo es claro que los gobiernos ya establecidos deben enfocarse en el fortalecimiento del derecho y adoptar la soberanía popular como principio a menos que deban someterse a los resultados de las revoluciones.

Para finalizar, aunque Kant se acoge al espíritu inicial de la Revolución Francesa, no accedió a consentir que el pueblo tuviera el derecho a ejecutarla por permanecer en medio de toda condena a la subordinación y porque repudiaba la anarquía y sus derivaciones. Por esto, se inclinó por la afirmación de la soberanía popular como modelo por excelencia y como imperativo para toda voluntad dirigente. Es por eso que, para Kant, la forma legítima para que predomine el valor de la libertad es la reforma; ya que esta impide que se desarrolle la violencia y para poder lograrlo el costo a pagar es la represión como deber sin ánimo a una resistencia cuando el gobierno se torne despótico; pese a que es la misma naturaleza o estado natural el que orienta al pueblo hacia la libertad utilizando frecuentemente las revoluciones como su instrumento, lo que conlleva a que admitamos dichas revoluciones siempre y cuando se den de manera progresista y no como método para guiar nuestro discernimiento político. Es evidente que ni en los textos de Kant ni en su ingenio cabe la incorporación de la barbaridad o el desinterés ante la perversidad de los demás, ya sea perversidad sufrida o ejercida 
por nuestro igual. De igual forma, en todo el pensamiento político kantiano no es admisible la confabulación con la tiranía ni con la sumisión. Así, en Kant el actuar moralmente es muy explícito y si se asume su postura como guía no se debería engañar al soberano ni practicar la coacción sin salvedades.

\section{Referencias}

Arendt, H. (2012). Conferencias sobre filosofía política de Kant. Barcelona: Paidós.

Barrientos, M. E. L. (2001). Los escritos políticos de Immanuel Kant. Realidad: Revista de Ciencias Sociales y Humanidades, (84), 847-874.

Bau, C. S. O. (2004). Kant: lecturas para el estudio de la desobediencia civil. Daimon Revista Internacional de Filosofía, (33), 187-194.

Beade, I. (2007). Liberalismo y republicanismo en la concepción kantiana de "ciudadanía". Reflexión Política, 9(17), 58-74.

Beade, I. (2009). Consideraciones acerca de la concepción kantiana de la libertad en sentido político. Revista de filosofía, 65, 25-41.

Bilbeny, N. (1989). Kant y la Revolución Francesa: refutación del derecho de resistencia civil. Anuario de filosofía del derecho, (6), 23-32.

Ceballos, R. (2015). El derecho de resistencia en Kant. Discusiones Filosóficas, 16(27), 105-125, doi: 10.17151/difil.2015.16.27.7.

Flores Vega, M. y Espejel Mena, J. (2008). Corrupción y transparencia: una aproximación desde la filosofía política de Immanuel Kant. Espacios Públicos, 11(21), 44-63.

Kant, I. (1986). Teoría y Práctica. En torno al tópico: "Tal vez esto sea correcto en teoría, pero no sirve para la práctica". Madrid: Tecnos.

Kant, I. (1993). La Metafísica de las Costumbres. Barcelona: Altaya.

Kant, I. (2003a). ¿Qué es ilustración? Y otros escritos de ética, política y filosofía de la historia. Madrid: Alianza Editorial.

Kant, I. (2003b). El conflicto de las facultades. Madrid: Alianza Editorial.

Kant, I. (2005). Crítica de la Razón Práctica. Ciudad de México: Fondo de Cultura Económica. 
Kant, I. (2012). Sobre la Paz Perpetua. Madrid: Alianza Editorial.

Korsgaard, C. (1996). Tomar la ley en nuestras propias manos: Kant sobre el derecho a la revolución. En D. M. Granja y T. Santiago (eds.), La paz y el ideal cosmopolita de la ilustración. Madrid: Tecnos.

Mirete Navarro, J. (1986). Kant y T. Hobbes: pacto social y posibilidad de resistencia al poder político. Anales de Derecho, 9, 133-142. Recuperado de http://revistas.um.es/analesderecho/article/view/82721.

Onfray, M. (2011). Política del rebelde. Tratado de resistencia e insumisión. Barcelona: Anagrama. 